\title{
Artificial Intelligence-Based Hole Quality Prediction in Micro-Drilling Using Multiple Sensors
}

\author{
Jitesh Ranjan ${ }^{1}$, Karali Patra ${ }^{1, *}$, Tibor Szalay ${ }^{2}\left(\mathbb{D}\right.$, Mozammel Mia $\left.{ }^{3}{ }^{(}\right)$, Munish Kumar Gupta ${ }^{4}(\mathbb{D}$, \\ Qinghua Song ${ }^{4}\left({ }^{\circ}\right.$, Grzegorz Krolczyk $\left.{ }^{5}{ }^{(}\right)$, Roman Chudy ${ }^{5}$, Vladislav Alievich Pashnyov ${ }^{6}$ and \\ Danil Yurievich Pimenov 6 (iD \\ 1 Department of Mechanical Engineering, Indian Institute of Technology Patna, Patna-801103, India; \\ jitesh4u89@gmail.com \\ 2 Department of Manufacturing Science and Engineering, Budapest University of Technology and Economics, \\ H-1111 Budapest, Hungary; szalay@manuf.bme.hu \\ 3 Department of Mechanical Engineering, Imperial College London, Exhibition Rd., London SW7 2AZ, UK; \\ m.mia19@imperial.ac.uk \\ 4 Key Laboratory of High Efficiency and Clean Mechanical Manufacture, Ministry of Education, School of \\ Mechanical Engineering, Shandong University, Jinan 250100, China; munishguptanit@gmail.com (M.K.G.); \\ ssinghua@sdu.edu.cn (Q.S.) \\ 5 Faculty of Mechanical Engineering, Opole University of Technology, 76 Proszkowska St., 45-758 Opole, \\ Poland; g.krolczyk@po.opole.pl (G.K.); r.chudy@po.edu.pl (R.C.) \\ 6 Department of Automated Mechanical Engineering, South Ural State University, Lenin Prosp. 76, \\ Chelyabinsk 454080, Russia; alich74@rambler.ru (V.A.P.); danil_u@rambler.ru (D.Y.P.) \\ * Correspondence: kpatra@iitp.ac.in; Tel.: +91-6123028012
}

Received: 23 December 2019; Accepted: 3 February 2020; Published: 7 February 2020

\begin{abstract}
The prevalence of micro-holes is widespread in mechanical, electronic, optical, ornaments, micro-fluidic devices, etc. However, monitoring and detection tool wear and tool breakage are imperative to achieve improved hole quality and high productivity in micro-drilling. The various multi-sensor signals are used to monitor the condition of the tool. In this work, the vibration signals and cutting force signals have been applied individually as well as in combination to determine their effectiveness for tool-condition monitoring applications. Moreover, they have been used to determine the best strategies for tool-condition monitoring by prediction of hole quality during micro-drilling operations with $0.4 \mathrm{~mm}$ micro-drills. Furthermore, this work also developed an adaptive neuro fuzzy inference system (ANFIS) model using different time domains and wavelet packet features of these sensor signals for the prediction of the hole quality. The best prediction of hole quality was obtained by a combination of different sensor features in wavelet domain of vibration signal. The model's predicted results were found to exert a good agreement with the experimental results.
\end{abstract}

Keywords: micro drilling; vibration; cutting force; wavelet packet; adaptive neuro fuzzy inference system

\section{Introduction}

Due to the emergence of the miniaturization of products in aerospace, biomedical, communication, electronics and automotive industries, the low cost of such miniaturized products with their best-of-class quality makes them suitable for extensive use of micro-machining processes. The adopted micro-machining processes include microturning [1,2], micromilling [3-6], microdrilling [7,8]. Micromachining is generally defined as the machining process that produces miniature component or feature in of the range of $1 \mu \mathrm{m}$ to $999 \mu \mathrm{m}$ [9]. Several non-conventional methods such as micro electric discharge machining ( $\mu \mathrm{EDM}$ ) [10-12], laser micromachining [13,14], ultrasonic [15-17], electron 
beam machining (EBM) $[18,19]$, etc. are mostly used to produce miniaturized product/feature this range. However, these methods are inferior to conventional machining due to some constraints like relevance only to certain shapes and non-suitability of a wide range of material types. On the other hand, mechanical micromachining methods which can produce any arbitrary shapes and are applicable to almost each type of material have wide acceptance to fabricate miniaturized products or micro-features [20]. The commercial micro tools are now widely manufactured, nevertheless it is difficult to measure wear and determine the fractures of such small size tools. Therefore, tool-condition monitoring of micromachining is crucial to improve the productivity and reliability of the process [21,22]. Effective monitoring system can provide precise estimation of tool wear with diverse cutting conditions and also provides operational safely for the operator [23-25].

Indirect monitoring is based on different cutting parameters by the different sensor signals such as thrust force [26-28], torque [29], current [30,31], spindle power [32], computer vision [33,34], vibration [35,36], acoustic emission [37], etc. These indirect parameter measurements are related to the tool condition. Through these signals, we analyze the cutting condition as well as tool condition by various signal processing techniques namely time domain signal, fast Fourier transform, wavelet packets transform and other higher-order transformations [38,39]. Kim et al. [26] used a force signal to monitor tool condition during micro hole drilling. Torque signal has also been extensively used for monitoring tool condition. In a drilling operation, torque increases as the tool wear increases. Oh et al. [30] investigated drill wear reduction in macro-drilling using a torque control method though measurement of a spindle motor current. Vibration signals are widely used for condition monitoring. The main advantages of the study of vibration signal are its ease of implementation as compared to other signals and no modification is required to the workpiece and fixture. Huang et al. [35] used vibration signals to monitor tool condition. Input impedance of driving motor measure features the same principle as torque, because they both focus on the amount of power used in the machining process. Fu et al. [40] used input impedance of driving motor to monitor tool condition during micro drilling. Kim et al. [26] investigated drill wear on the basis of spindle motor power. However, for effective monitoring of tool conditions in the complex cutting mechanism, a sensor fusion is needed that can eliminate the problems of the limited bandwidth of individual sensor [25,41,42]. Segreto et al. [41] analyzed machined surface integrity through multiple sensor monitoring based on cutting force, acoustic emission and vibration signal analysis. Plaza et al. [42] also proposed multi-sensor data fusion for in-process quality control of machining based on cutting force, vibration and acoustic emission signals. Similarly, Malekian et al. [25] showed improvement of tool-wear monitoring in mechanical micro-milling using multiple sensor data fusion based on all the aforementioned three sensor signals.

Machining operations, specifically, the micro drilling process, involve models which are highly non-linear. Analytical models divulge better results of wear progression mechanism, but sometimes they are less accurate because of simplifications due to several assumptions. Artificial intelligence-based systems such as the artificial neural network (ANN) [43-45], the convolutional neural network (CNN) [46,47] and the adaptive neural fuzzy inference system (ANFIS) [48] are considered feasible, consistent and smart approaches for predicting the condition of cutting tools. These techniques can realize non-linear relations among machining parameters, process signals and tool states for their high fault tolerance and adaptability features. Rahman et al. [43] applied ANN in turning operations for monitoring wear, chip breaking and tool chatter. Sharma et al. [44] applied ANN for predicting tool wear from cutting forces, vibrations and acoustic emission signals. Patra et al. [45] also used an ANN-based model for micro-drill condition monitoring by using vibration signals. In recent works, Wang et al. [46] and Cao et al. [47] showed that convolutional neural network can be more effective and faster than the conventional networks like ANN, support vector machine (SVM), etc. for prediction/identification of system performances through multi-sensor data.

The application of ANFIS is also widespread; it is a hybrid modelling technique that comprises fuzzy logic and ANN technique. In this hybrid technique, a fuzzy model is first developed using the rules extracted from the input output data of the system in hand. Then, the ANN is used to fine tune 
the rules of the fuzzy model and the final ANFIS model of the system is obtained. Malekian et al. [25] used features of acoustics emission, force and acceleration sensors, cutting parameters and the tool edge radius value as input to the neuro-fuzzy algorithm to estimate tool conditions (good, average, bad). Beruvides et al. [48] used ANFIS for predicting tool wear in micro-drilling.

For an effective ANFIS-based tool condition monitoring system, it is necessary to use data of process signals for a number of drilled holes up to the drill breakage for a variety of cutting conditions. In this work, the vibration signals and cutting-force signals have been applied individually and in combination to determine their effectiveness for tool condition monitoring applications in terms of hole quality and also to determine best strategies for tool condition monitoring. The time domain and wavelet features of these signals have been used in ANFIS models to predict the hole quality. Furthermore, the hole quality prediction by wavelet features of vibration signal was compared with the same by the time domain features.

The purpose of this article is to predict the quality of the holes obtained in micro-drilling through monitoring the condition of the tool and detecting the tool breakage by thrust force, torque and vibration signals using artificial intelligence.

\section{Materials and Method}

Micro-drilling experiments were conducted on CNC micro machining centre (Model DT110, Mikrotools Pte Ltd, Singapore) as shown in Figure 1. A triaxial accelerometer and a Kistler Minidyn 9256C2 dynamometer (Aachen, Germany) were used to record the vibration signal, force signal and torque signal. The sampling frequency of 10,000 Hz was set in NIPXI 1052 data acquisition system (National Instruments, Austin, TX, USA) for obtaining vibration signals. The force and torque were acquired by charge amplifier 5070A (Kistler, Aachen, Germany) and dynoware software with a sampling rate of 1000 samples/s. Solid carbide drills (manufactured by Seco Tools GmBH, Fagersta, Sweden) with diameter of $0.4 \mathrm{~mm}$ were applied on austenitic stainless steel workpiece to make blind hole of $1.0 \mathrm{~mm}$ depth.

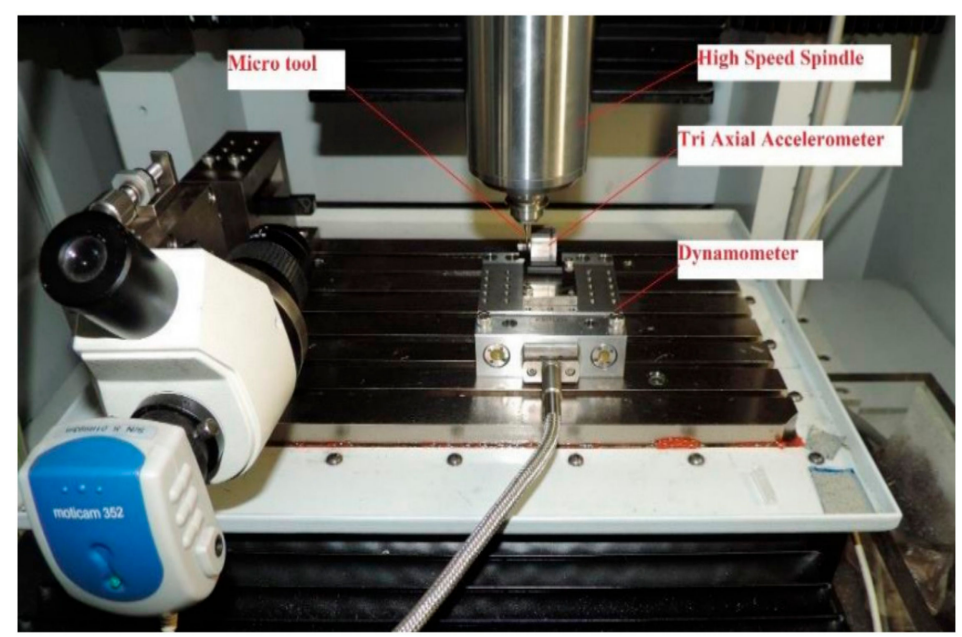

Figure 1. Experimental setup for micro-drilling.

The experimental conditions are shown in Table 1. As the feed value is very small (in micrometer range) in microdrilling, high spindle speed generally is used to reduce the machining time for hole making. Anand et al. [49] used very high cutting speed (15-40 m/min corresponding to 10,000-25,000 $\mathrm{rpm}$ ) and showed that the specific thrust force value does not vary much by increasing the cutting speed from the recommended cutting speed range of the manufacturer. Therefore, this work used cutting speed range of $12.8-24 \mathrm{~m} / \mathrm{min}(10,186 \mathrm{rpm}$ to $19,099 \mathrm{rpm})$. 
Table 1. Experimental cutting conditions.

\begin{tabular}{ccccc}
\hline $\begin{array}{c}\text { Cutting Condition } \\
\text { (CC) }\end{array}$ & $\begin{array}{c}\text { Drill Diameter, } \boldsymbol{D} \\
(\mathbf{m m})\end{array}$ & $\begin{array}{c}\text { Spindle Speed, } \boldsymbol{n} \\
\mathbf{( \mathbf { r p m } )}\end{array}$ & $\begin{array}{c}\text { Feed Rate, } f_{\boldsymbol{r}} \\
(\mathbf{m m} / \mathbf{r e v})\end{array}$ & $\begin{array}{c}\text { No. of } \\
\text { Hole }\end{array}$ \\
\hline CC1 & 0.4 & 10,186 & 0.003 & 44 \\
CC2 & 0.4 & 14,186 & 0.002 & 79 \\
CC3 & 0.4 & 19,099 & 0.001 & 41 \\
CC4 & 0.4 & 19,099 & 0.003 & 11 \\
CC5 & 0.4 & 14,186 & 0.003 & 24 \\
\hline
\end{tabular}

There is also another reason for using higher cutting speed. The higher cutting speed (spindle rpm) was shown to accelerate tool wear [50]. Therefore, by using higher cutting speed, we could get increased cutting force and vibration with less number of drilled hole. This helps us to develop the model will less number of experiments.

\section{Results and Discussion}

\subsection{Signal Analysis}

\subsubsection{Time Domain Features of Process Signals}

The time domain features extracted from different process signals are mainly arithmetic mean, root mean square (RMS) value, kurtosis, and standard deviation [51]. Among these features, RMS value is the most common one that represents most of the signal energy. The time domain features extracted from vibration signal is root mean square (RMS), whereas, mean value of thrust force and mean value of torque are the two other time domain features. The variations of vibration, thrust force and torque features with respect to the hole numbers before the tool breakage of different cutting condition are shown in Figure 2a-c. From Figure 2a. it is clearly seen that at constant feed rate $f_{r}=0.003 \mathrm{~mm} / \mathrm{rev}$ and different spindle speeds $n=14,186 \mathrm{rpm}$ (CC5) and $n=19,099 \mathrm{rpm}$ (CC4), an increase in rms of vibration $\mathrm{Z}$ signals is observed with respect to lower spindle speed $n=10,186 \mathrm{rpm}$ (CC1). A similar trend with constant spindle speed $n=14,186 \mathrm{rpm}$ and different feed rates $f_{r}=0.002 \mathrm{~mm} / \mathrm{rev}$ (CC2) and $f_{r}=0.003$ $\mathrm{mm} / \mathrm{rev}$ (CC5) is also observed. In addition, for feed rate $f_{r}=0.001 \mathrm{~mm} / \mathrm{rev}$, spindle speed $n=19,099$ rpm (CC3), the rms of vibration $Z$ signals increase after 20 number holes and increase sharply after 30 number holes. For feed rate $f_{r}=0.002 \mathrm{~mm} / \mathrm{rev}$, spindle speed $n=14.186 \mathrm{rpm}(\mathrm{CC} 3), \mathrm{rms}$ of vibration $\mathrm{Z}$ signals increase after 37 number hole and increase sharply after 73 number hole. These phenomena can be explained by the growth of flank wear micro drill. Figure $2 b$ shows that the mean torque increases with increasing hole number. However, with increasing spindle speed from $n=10,186 \mathrm{rpm}$ (CC1), $n=14,186 \mathrm{rpm}$ (CC5) to $n=19,099 \mathrm{rpm}$ (CC4) and constant feed feed rate $f_{r}=0.003 \mathrm{~mm} / \mathrm{rev}$, we observe a decrease in mean torque. Moreover, an increase in feed rate from $f_{r}=0.002 \mathrm{~mm} / \mathrm{rev}$ (CC2) to $f_{r}=0.003$ $\mathrm{mm} / \mathrm{rev}$ (CC5) and a constant spindle speed $n=14,186 \mathrm{rpm}$ on the contrary leads to an increase in mean torque. Figure $2 \mathrm{c}$ shows that mean thrust force tends to increase with increasing hole, but with less intensity compared to mean torque. However, with increasing spindle speed from $n=10,186 \mathrm{rpm}$ (CC1), $n=14,186 \mathrm{rpm}$ (CC5) to $n=19,099 \mathrm{rpm}$ (CC4) and constant feed feed rate $f_{r}=0.003 \mathrm{~mm} / \mathrm{rev}$, we observe increase in mean thrust force. A similar trend at feed rate from $f_{r}=0.002 \mathrm{~mm} / \mathrm{rev}$ (CC2) to $f_{r}=0.003 \mathrm{~mm} / \mathrm{rev}$ (CC5) and a constant spindle speed $n=14,186 \mathrm{rpm}$ leads to an increase in mean thrust force. With increasing feed rate from $f_{r}=0.001 \mathrm{~mm} / \mathrm{rev}$ (CC3) to $f_{r}=0.003 \mathrm{~mm} / \mathrm{rev}$ (CC4) and a constant spindle speed $n=19,099 \mathrm{rpm}$, the trend also increases in mean thrust force. 


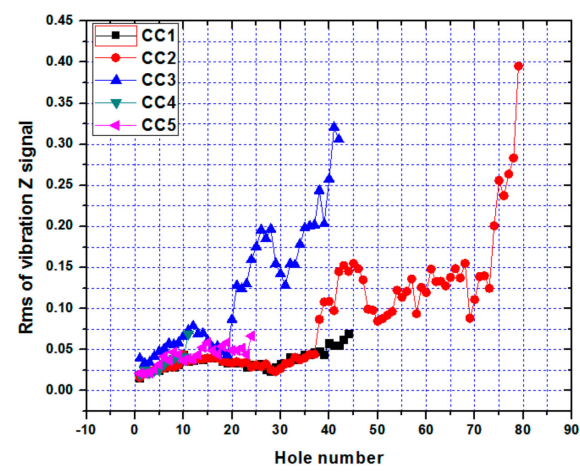

(a)

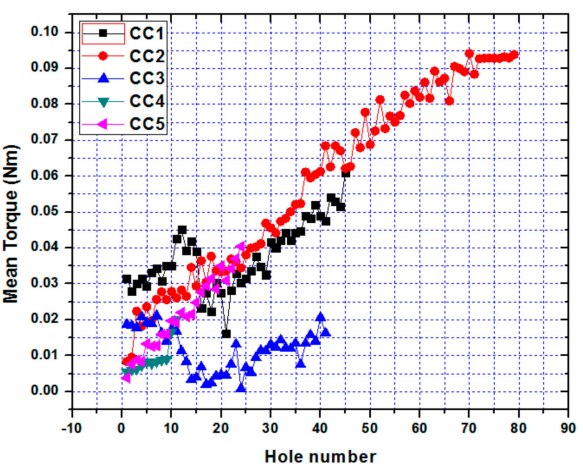

(b)

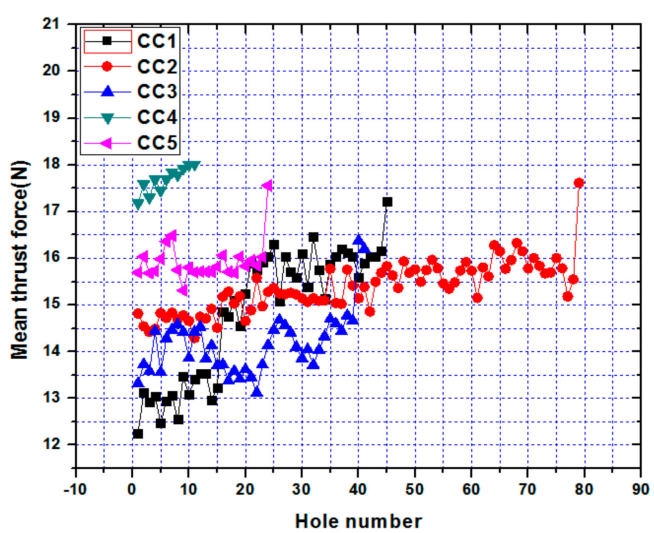

(c)

Figure 2. The variations of (a) vibration, (b) thrust force and (c) torque features with respect to the hole numbers.

It can be seen that amplitudes of these signals increase non-linearly with the number of holes drilled. With increase in hole number, tool wear increases that contributes to increase RMS and mean values of these signals $[23,45]$ shown in the figures. It can also be seen that RMS values of vibration signals increase suddenly just before the breakage of the tool [45]. On the other hand, the magnitudes of torque and thrust signals do not show any sudden change prior to tool breakage [23].

\subsubsection{Wavelet Packet Features of Vibration Signals}

As mean and RMS values of time domain features are determined by considering the whole signals, these are likely to be affected by the noise and disturbance present in the drilling process. To eliminate the noise and disturbances, many attempts have been made earlier to extract features in the frequency domain and the time-frequency domain [48,52]. Among different time-frequency domain signal processing methods, the most common is the wavelet packet transform which can overcome the poor time localization of a fast Fourier transform (FFT) and loss of important information due to not consideration of the detail part in case of a discrete wavelet transform (DWT). In this work, the wavelet packet transform is performed to decompose the vibration signal (up to $5 \mathrm{kHz}$ ) into 8 frequency bands ( 8 wavelet packets) up to level 3 [53]. These packets are denoted as packet $(3,0)$, packet $(3,1)$, packet $(3,2)$, packet $(3,3)$, packet $(3,4)$, packet $(3,5)$, packet $(3,6)$ and packet $(3,7)$ corresponding to frequency range of $(0-0.625 \mathrm{kHz}),(0.625-1.25 \mathrm{kHz}),(1.25-1.875 \mathrm{kHz}),(1.875-2.5 \mathrm{kHz}),(2.5-3.125 \mathrm{kHz})$, $(3.125-3.75 \mathrm{kHz}),(3.75-4.375 \mathrm{kHz})$ and $(4.375-5 \mathrm{kHz})$, respectively.

Wavelet packet coefficients are estimated using Daubechies 8 wavelet function. Wavelet packet feature $\left(C_{i j}\right)$ which is the RMS value of the wavelet coefficients for a packet is determined to relate the condition of the tool at different cutting conditions. Here, $i$ is the decomposition level and $j$ stands for the packet number at the ith level. 
Figure 3a,b shows the time signal comparison of the first hole and 79th hole of the cutting condition (CC2). It can be observed that the amplitude of vibration for the 79th hole is very high in comparison with the same for the 1st hole as tool wear becomes severe for later case. This leads to tool failure after the 79th hole. The observation is in the similar line to that of trends reported earlier [45]. Figure 3c,d present all the 8 wavelet packets of 1 st hole and the 79th hole (before the tool breakage), respectively. It can be observed that in packet $(3,4),(3,5)$ and $(3,7)$ the amplitude variation was very high compared with the 1st hole packet; however, the other packet's amplitude variation is comparably very low.

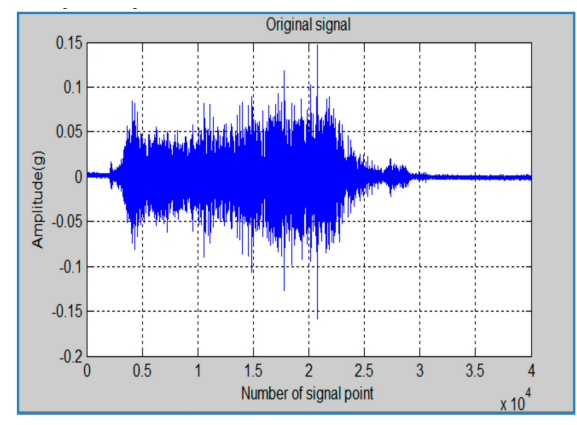

(a)
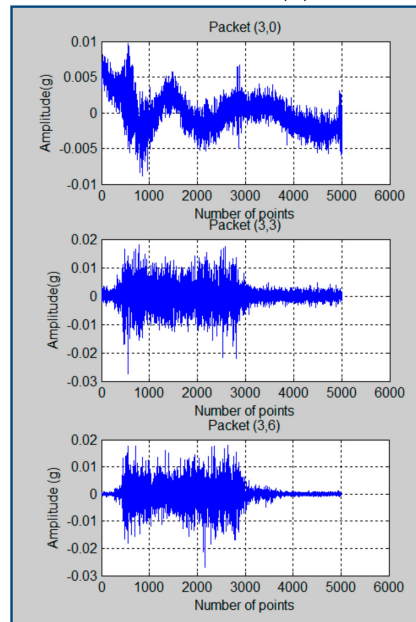

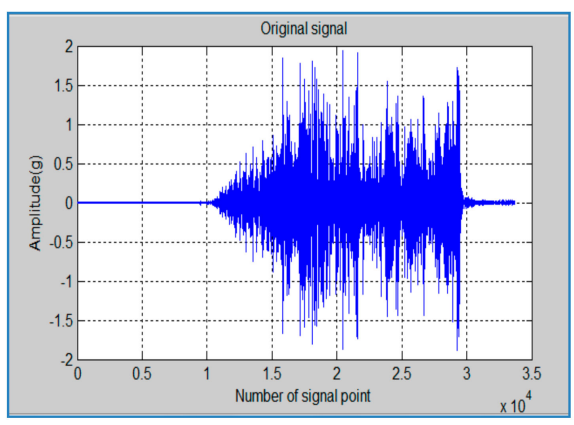

(b)
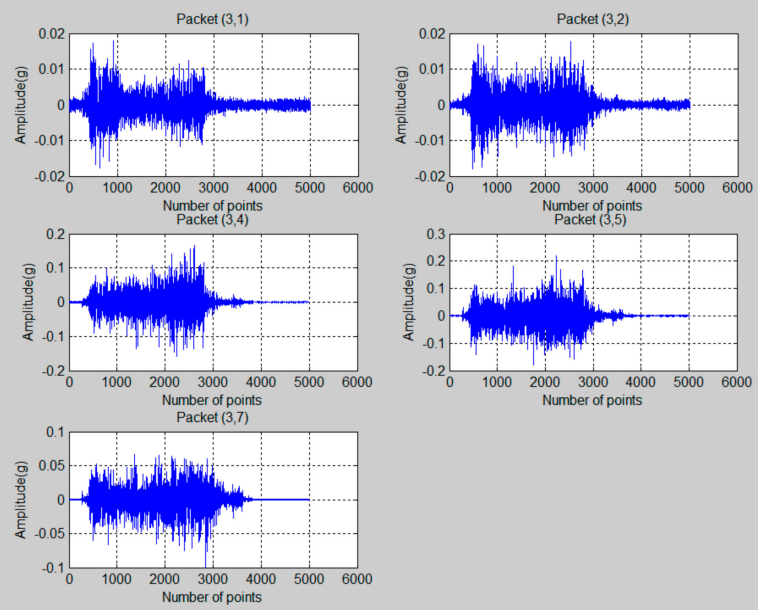

(c)
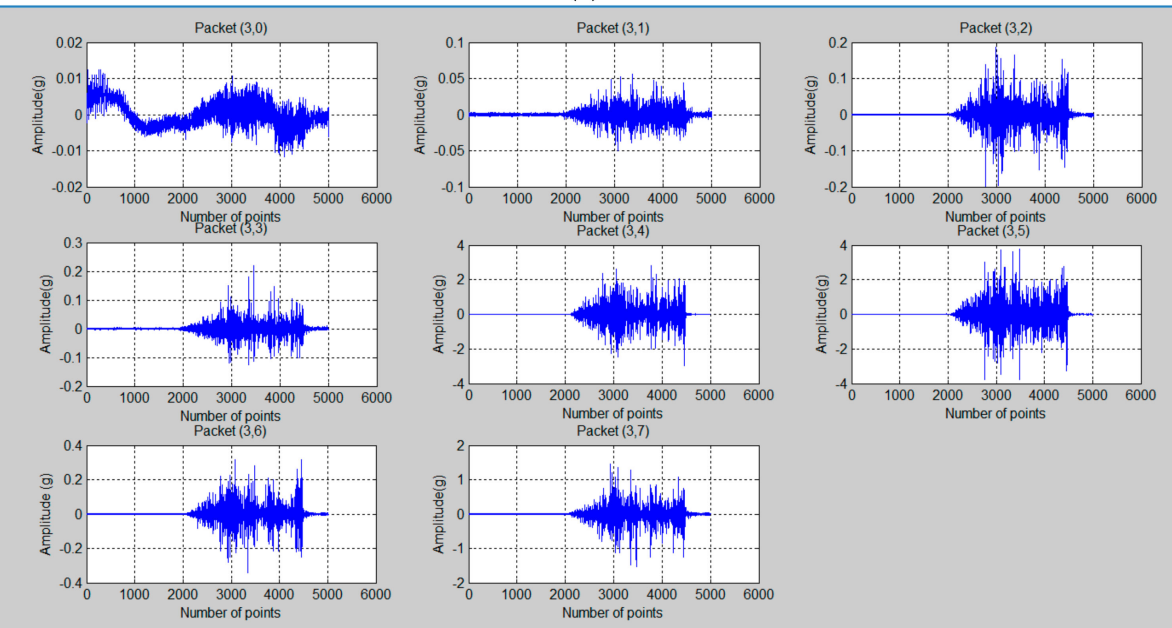

(d)

Figure 3. Time signal for (a) 1st hole and (b) 79th hole of vibration. The wavelet packet signal for (c) 1st hole and (d) 79th hole of vibration. Data taken in $\mathrm{Z}$ direction, and the signal is of cutting condition CC2. 
Each wavelet packet carries information on the vibration signal in terms of wavelet coefficients. But some of the packets also contain noise or less important information depending on the process dynamics [50]. Figure 4a-e shows variations of wavelet coefficients with hole number for all 5 cutting conditions. In all 5 plots, 3 or 4 frequency bands such as C34, C35, C37 have non-linearly increasing trends as compared to other wavelet packets of the first hole to till brakage hole. The less amplitude packets contain noise and are not affected by the tool condition. Features that show increasing trends have been taken as input of soft computing techniques (i.e., ANFIS).

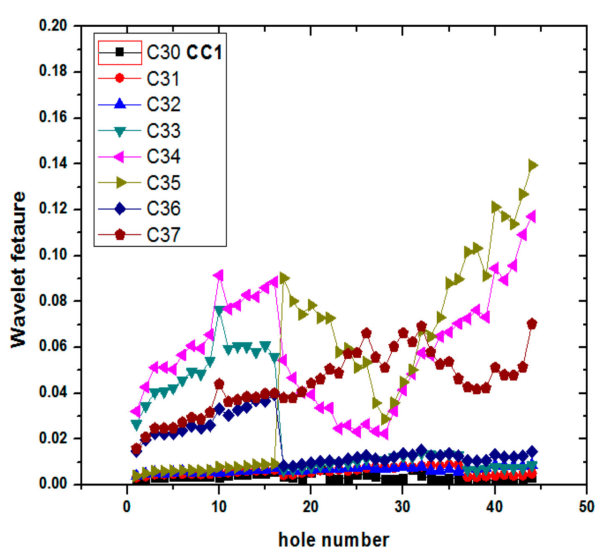

(a)

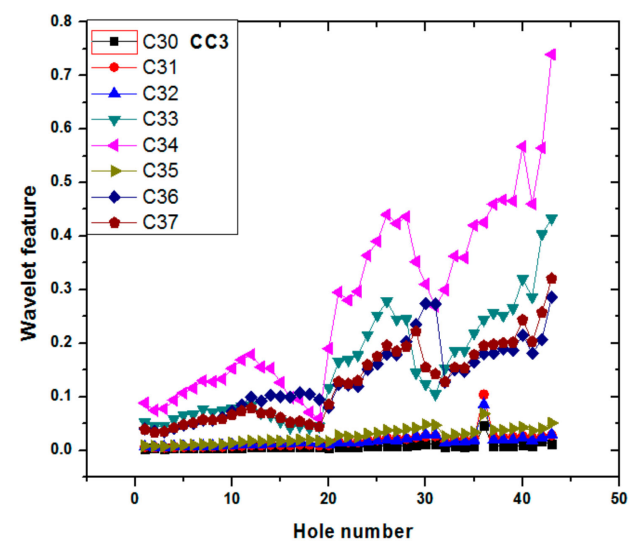

(c)

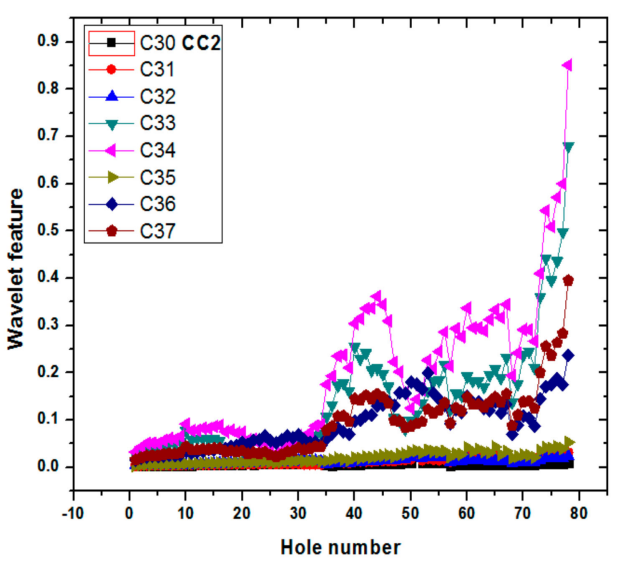

(b)

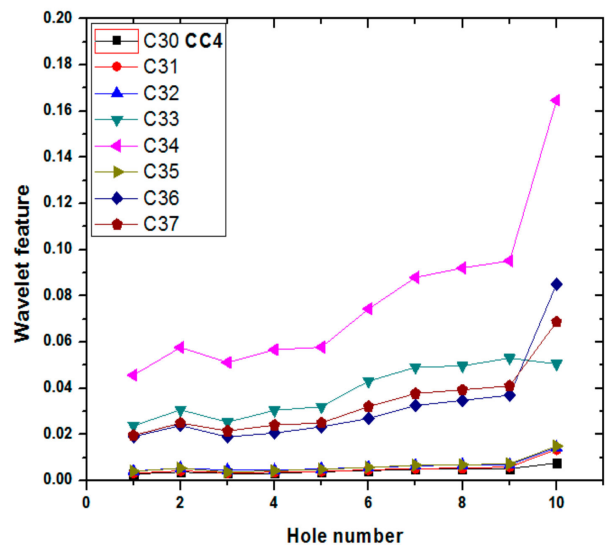

(d)

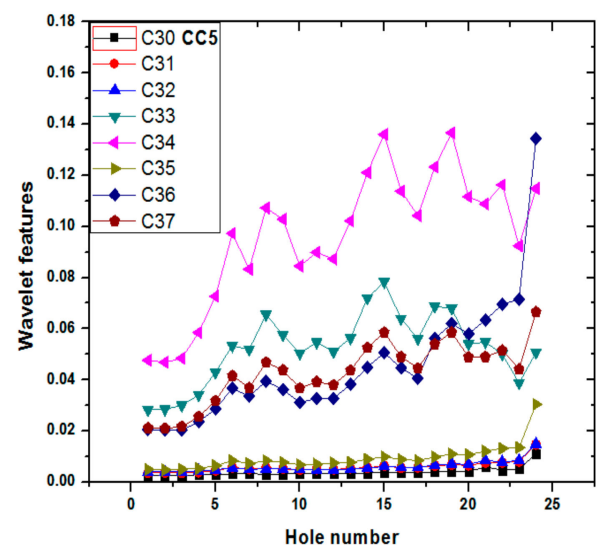

(e)

Figure 4. Wavelet packet features for different cutting conditions (a) CC1; (b) CC2; (c) CC3; (d) CC4; (e) CC5 from $1^{\text {st }}$ hole to last hole before drill breakage. 


\subsection{Hole Quality}

The predictability and effectiveness of the two models are based on the hole quality. Typically, the hole roundness error is used as a measure of hole quality in drilling [54]. To determine the roundness error, maximum circles are inscribed inside and outside the hole profile and their radii are defined as outer radius and inner radius of the hole. The difference of outer radius and inner radius of the hole is called roundness error [55]. For each cutting condition, the images of all drilled holes before the drill breakage were captured by a high-resolution microscope, and its outer and inner radius of each hole are determined by digimizer software tool as shown in Figure 5a-c for the 1st, 40th and 79th holes of cutting condition CC2. The hole roundness error is calculated for individual hole and plotted against hole number for different cutting conditions as shown in Figure 5d. Comparing the influence of various values of cutting speeds and feeds from Figure 5 the following relationships are visible. With a constant feed rate $f_{r}=0.003 \mathrm{~mm} / \mathrm{rev}$, with increase of cutting speed $n=14,186 \mathrm{rpm}$ (CC5) and $n=19,099 \mathrm{rpm}$ (CC4) we have an increase in the average roundness error compared to that of cutting speed of 10,186 rpm (CC1).Similarly, with a constant spindle speed of $\mathrm{n}=14,186 \mathrm{rpm}$ and different feed rate $f_{r}=0.002 \mathrm{~mm} / \mathrm{rev}$ (CC2) and $f_{r}=0.003 \mathrm{~mm} / \mathrm{rev}$ (CC5), we get the increase of average roundness errors with increase in feed. A similar situation is observed with a constant spindle speed of $n=19,099 \mathrm{rpm}$ and different feed speed $f_{r}=0.001 \mathrm{~mm} / \mathrm{rev}$ (CC3) and $f_{r}=0.003 \mathrm{~mm} / \mathrm{rev}$ (CC4). In addition, for CC2 and CC5 it is clearly seen that with a hole number of 75 and 36, respectively, the average roundness error increases sharply. This can be explained by the development of catastrophic wear of the micro drill.

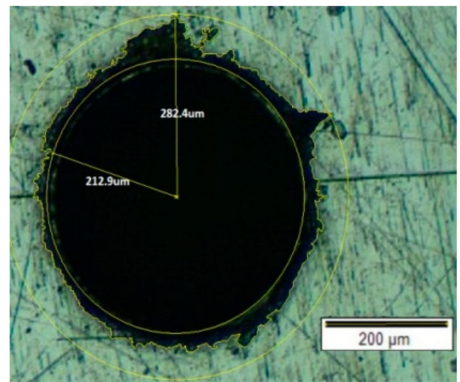

(a)

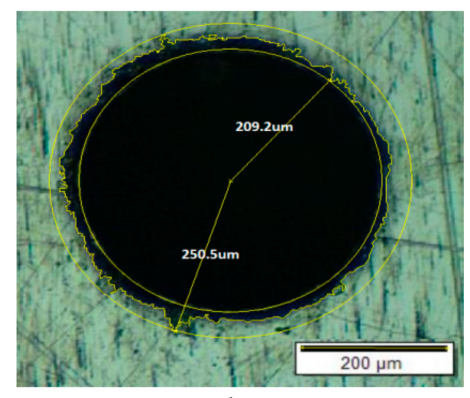

(b)

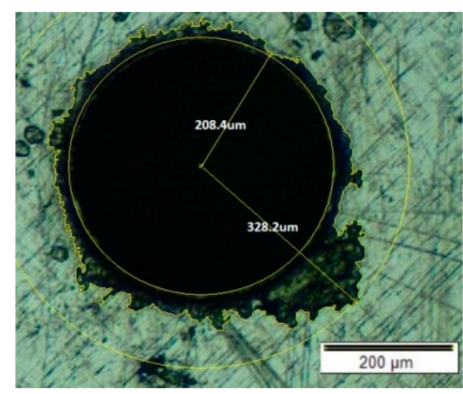

(c)

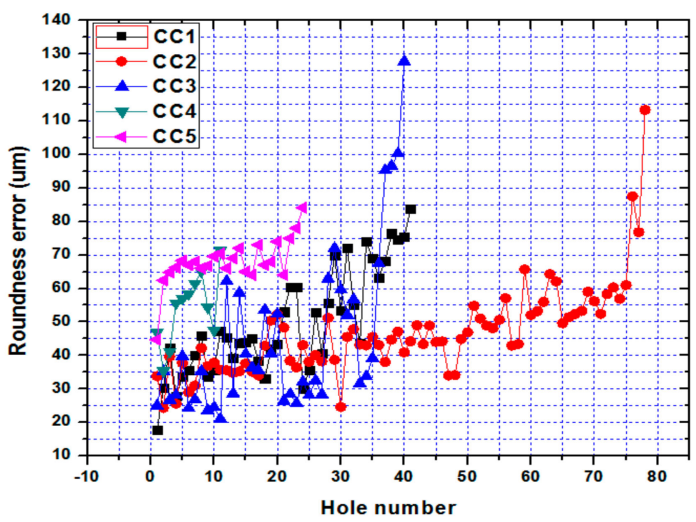

(d)

Figure 5. Images of drilled holes (a) no.1, (b) no. 40, and (c) no. 79 for the cutting condition 2 (CC2); (d) variations of roundness error with respect to the hole numbers with different cutting conditions.

The roundness error value increases non-linearly with the drilled hole numbers. The nonlinear increase of roundness error with increasing hole number is related to the increase of cutting forces and vibration magnitudes. Increase in tool deflection due to change in cutting forces and vibration amplitude increases the roundness error [40]. Furthermore, it can be observed that the trend of roundness error is similar to that of the vibration with respect to the drilled hole number. 


\subsection{Tool Condition-Monitoring Based on Hole Quality Prediction Using Multiple Sensors}

\subsubsection{Adaptive Neuro Fuzzy Inference System (ANFIS) Model for Time Domain Signals}

As the hole roundness error depends on the tool condition and cutting conditions, prediction of hole quality through input process signals (vibration, thrust and torque) at any cutting condition can tell the cutting tool condition. The decision can be taken whether the tool is still acceptable or not based on the hole quality. An adaptive neuro-fuzzy inference system (ANFIS) has been introduced to relate input process signals with hole quality parameter. The Matlab ANFIS tool has been used to develop the neuro-fuzzy network. In ANFIS model, fuzzy inference system is superimposed to the neural network. The neural network layer has input, output and a hidden layer. The hidden layer is imposed by fuzzy inference system (i.e., membership function layer and rule-based layer) and an activation function. Features extracted from different sensors and the cutting conditions were used as the inputs to this ANFIS to determine the output parameter, i.e., hole quality. Figure 6a shows the inputs, membership values, rules and combined output architecture of ANFIS model. Here, input parameters $\mathrm{X} 1, \mathrm{X} 2$ and $\mathrm{X} 3$ are the mean thrust $(\mathrm{Fz})$, mean torque $(\mathrm{Mz})$ and RMS vibration (Az) from time domain signals.

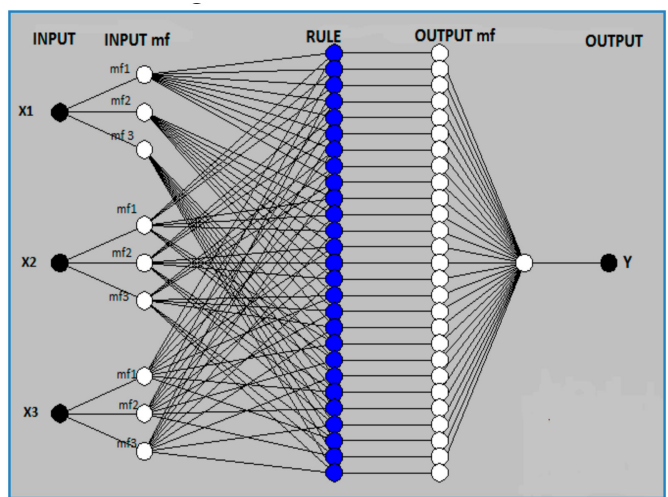

(a)

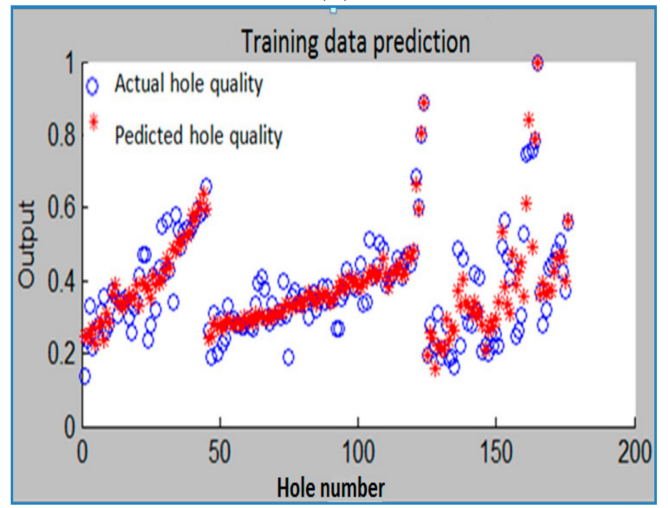

(c)

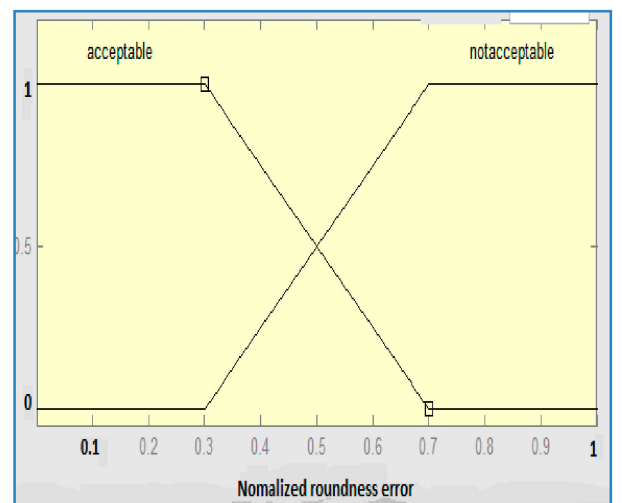

(b)

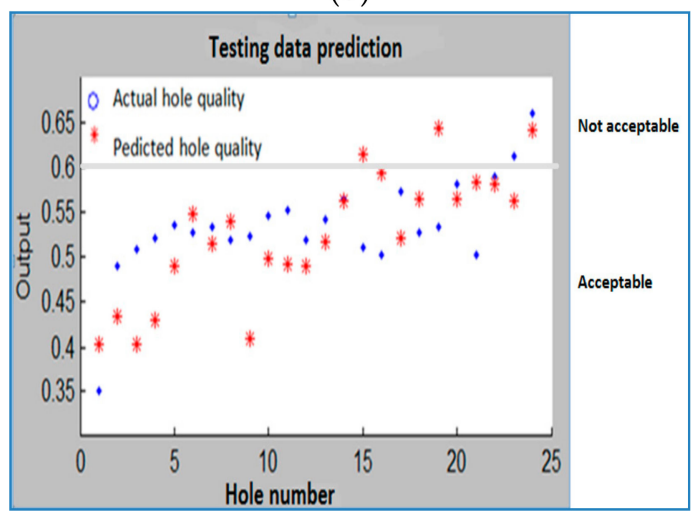

(d)

Figure 6. (a) Different input, different membership value, rules and combined output architecture; (b) Trapezoidal function of normalized hole quality with two membership function; (c) Prediction accuracy for training data; (d) Prediction accuracy for testing data.

For training, data from sensor features, i.e., RMS value of vibration signal, mean value of thrust force and torque at 4 cutting conditions (CC1 to CC4 of 175 holes) have been employed. For testing, data with same sensor features from another cutting condition data (CC5 of 24 holes) have been used. Hole quality value could be assigned as an output. Based on hole-quality prediction, we identified the tool condition as 'acceptable' or 'not acceptable'. From Figure 5, it can be observed that roundness errors of the initial drilled holes at different cutting conditions remain in the range of 30-40 $\mu \mathrm{m}$, similar 
to the errors reported by Anand and Patra [54] for microdrilling with fresh cutting tools. Though with increase in hole number the roundness error increases, the value remains within $70 \mu \mathrm{m}$ for most of cutting conditions for most of the time. Thereafter, we observe a sudden increase of roundness error till the breakage of the microdrill. Therefore, hole roundness error has been considered 'acceptable' and 'not acceptable', corresponding to hole roundness less than $70 \mu \mathrm{m}$, and greater than $70 \mu \mathrm{m}$, respectively. Normalization of both input and output parameters have been conducted and these parameters lie between 0 and 1. A trapezoidal membership function has been chosen for both input and output. Figure $6 \mathrm{~b}$ define the acceptable and not acceptable hole quality with intersection regions. The presented results can help the operator or the control system to take proper tool changing decisions.

Table 2 lists the combinations of the sensor features, taken for training and testing. The minimum mean training error was 0.0639 for the data set with combination of all force, torque and vibration signal. The corresponding testing error was found to be 0.07037 . Figure $6 \mathrm{c}, \mathrm{d}$ compares the normalized predicted hole quality with the actual hole quality (roundness error) using training and testing data, respectively, obtained by combining mean thrust $(\mathrm{Fz})$, mean torque $(\mathrm{Mz})$ and RMS vibration (Az). Figure $6 \mathrm{~d}$ also shows the hole quality of acceptable and not acceptable values for the testing data against the hole number. The deviation of some of these data comes due to the non-linear feature of data. Nonlinear features of the data arise due to the uncertainty and complexity of the micromachining process. So we developed a model based on acceptable hole quality. Even though we found deviations of some of the data points, the mean testing error of the selected multi-sensor data fusion approach is low and acceptable. Among the employed strategies of hole-quality prediction, the best performance was given by fusion of different sensor signal; this is due to fact that it takes a wide range of signal bandwidth. At a wide range of bandwidth, the features extracted are more accurate and noise free.

Table 2. Adaptive neuro fuzzy inference system (ANFIS) performance for different combinations of time domain features.

\begin{tabular}{ccc}
\hline Input Signal & Mean Training Error & Mean Testing Error \\
\hline Thrust $\left(F_{z}\right)$ & 0.10418 & 0.30836 \\
Torque $\left(M_{z}\right)$ & 0.11599 & 0.28671 \\
Vibration $\left(A_{z}\right)$ & 0.083327 & 0.10583 \\
$F_{z}$ and $M_{z}$ & 0.083997 & 0.5762 \\
$F_{z}$ and $A_{z}$ & 0.071963 & 0.062799 \\
$M_{z}$ and $A_{z}$ & 0.07369 & 0.18667 \\
$F_{z}, M_{z}$ and $A_{z}$ & 0.063938 & 0.07037 \\
\hline
\end{tabular}

\subsubsection{ANFIS Model Using Wavelet Packet-Based Vibration Features}

An ANFIS model has also been developed where the inputs were high sensitive wavelet features of $\mathrm{Z}$ direction vibration signal at different cutting conditions and the output was the hole quality. The structure of the wavelet packet feature based ANFIS is similar to that shown in Figure 6a. For training, data of 3 highly sensitive wavelet features (C34, C35, C37) of vibration signals for 4 cutting conditions of 176 holes have been considered. For testing, data with same wavelet features of 24 holes of another cutting condition's data (CC5) have been employed. In this approach also the normalized values between 0 and 1 are used for all input and output parameters. After training, the ANFIS was ready to estimate tool condition based on hole-quality prediction with the testing data. By ANFIS model, the mean training error and the testing error of vibration signal was found as 0.054371 and 0.080652. Table 3 presents the performance comparison of ANFIS models using RMS vibration features and wavelet packet features of vibration signal in $\mathrm{Z}$ direction. The errors of training and testing steps are less in a wavelet packet approach as compared to a time domain approach. 
Table 3. Performance comparison of wavelet features and time feature by ANFIS model.

\begin{tabular}{|c|c|c|}
\hline \multirow{2}{*}{$\begin{array}{c}\text { Input Parameters (Z Direction } \\
\text { Vibration Signal) }\end{array}$} & \multicolumn{2}{|c|}{ ANFIS Model } \\
\hline & Mean Training Error & Mean Testing Error \\
\hline $\begin{array}{l}\text { Wavelet features of vibration (C34, } \\
\text { C35, C37) }\end{array}$ & 0.054371 & 0.080652 \\
\hline $\begin{array}{l}\text { Time domain feature, rms } \\
\text { vibration }\left(\mathrm{A}_{\mathrm{z}}\right)\end{array}$ & 0.083327 & 0.10583 \\
\hline
\end{tabular}

\section{Conclusions}

This work develops the indirect tool-monitoring techniques for monitoring tool condition and detecting tool breakage based on hole quality. For this purpose, features were extracted from the thrust force, torque and vibration signals. The following conclusions are drawn from this work:

- Cutting force signals, i.e., thrust and torque have been studied in the time domain, and vibration signals from the workpiece are studied in the time domain as well as the time frequency domain. The values of the extracted features increase for a continuing drilled hole and become the maximum before breakage.

- Prediction of drilled hole quality is better by considering all the appropriate features collectively rather than when they are considered individually. The results establish that the fusion of sensor signal features can produce higher accuracy of tool-condition prediction.

- Hole-quality prediction by ANFIS model reveals the best performance among the different monitoring strategies it is fusion of all the time signal feature. The wavelet packet-based approach is more accurate in prediction of hole quality as compared to time based approaches of vibration signals. Moreover, the different monitoring strategies are found to perform better in fusion of all sensor signal.

Author Contributions: Conceptualization, J.R.,K.P., T.S. and D.Y.P.; Methodology, J.R., K.P. and T.S.; Software, J.R. and K.P.; Validation, J.R., K.P. and T.S.; Formal Analysis, J.R., K.P. and T.S.; Investigation, J.R., K.P.,T.S., M.M., M.K.G., and D.Y.P.; Resources, J.R., K.P. and T.S.; Data Curation, J.R., K.P. and T.S.; Writing-Original Draft Preparation, J.R., K.P., T.S., M.M., M.K.G., Q.S., G.K., R.C., V.A.P. and D.Y.P.; Writing-Review and Editing, J.R., K.P., T.S., M.M., M.K.G., Q.S., G.K., R.C., V.A.P. and D.Y.P.; Visualization, J.R., K.P. and T.S.; Supervision, K.P., M.M., M.G. and D.Y.P.; Project Administration, K.P.; Funding Acquisition, K.P., G.K. and R.C. All authors have read and agreed to the published version of the manuscript.

Funding: This research was funded by DST, Govt. of India and NIH, Govt. of Hungary with grant number INT/HUN/P-01/2012 and TÉT_10-1-2011-0233, respectively.

Conflicts of Interest: The authors declare no conflict of interest.

\section{References}

1. Rao, R.V.; Rai, D.P.; Balic, J. Multi-objective optimization of machining and micro-machining processes using non-dominated sorting teaching-learning-based optimization algorithm. J. Intellig. Manuf. 2018, 29, 1715-1737. [CrossRef]

2. Boswell, B.; Islam, M.N.; Davies, I.J. A review of micro-mechanical cutting. Int. J. Adv. Manuf. Technol. 2018, 94, 789-806. [CrossRef]

3. Parenti, P.; Masato, D.; Sorgato, M.; Lucchetta, G.; Annoni, M. Surface footprint in molds micromilling and effect on part demoldability in micro injection molding. J. Manuf. Process. 2017, 29, 160-174. [CrossRef]

4. Pratap, T.; Patra, K. Fabrication of micro-textured surfaces using ball-end micromilling for wettability enhancement of Ti-6Al-4V. J. Mater. Process. Technol. 2018, 262, 168-181. [CrossRef]

5. Sahoo, P.; Pratap, T.; Karali, P. A hybrid modelling approach towards prediction of cutting forces in micro end milling of Ti-6Al-4V titanium alloy. Int. J. Mech. Sci. 2019, 150, 495-509. [CrossRef]

6. Sahoo, P.; Patra, K.; Singh, V.K.; Gupta, M.K.; Song, Q.; Mia, M.; Pimenov, D.Y. Influences of TiAlN coating and limiting angles of flutes on prediction of cutting forces and dynamic stability in micro milling of die steel (P-20). J. Mater. Process. Technol. 2020, 278, 116500. [CrossRef] 
7. Anand, R.S.; Patra, K. Mechanistic cutting force modeling for micro-drilling of CFRP composite laminates. CIRP J. Manuf. Sci. Technol. 2017, 16, 55-63. [CrossRef]

8. Hasan, M.; Zhao, J.; Jiang, Z. A review of modern advancements in micro drilling techniques. J. Manuf. Process. 2017, 29, 343-375. [CrossRef]

9. Masuzawa, T.; Tönshoff, H.K. Three-dimensional micromachining by machine tools. CIRP Ann. Manuf. Technol. 1997, 46, 621-628. [CrossRef]

10. Koyano, T.; Sugata, Y.; Hosokawa, A.; Furumoto, T. Micro electrical discharge machining using high electric resistance electrodes. Precis. Eng. 2017, 47, 480-486. [CrossRef]

11. Yang, F.; Bellotti, M.; Hua, H.; Yang, J.; Qian, J.; Reynaerts, D. Experimental analysis of normal spark discharge voltage and current with a RC-type generator in micro-EDM. Int. J. Adv. Manuf. Technol. 2018, 96, $2963-2972$. [CrossRef]

12. Abidi, M.H.; Al-Ahmari, A.M.; Umer, U.; Rasheed, M.S. Multi-objective optimization of micro-electrical discharge machining of nickel-titanium-based shape memory alloy using MOGA-II. Measurement 2018, 125, 336-349. [CrossRef]

13. Daemi, B.; Ekberg, P.; Mattsson, L. Lateral performance evaluation of laser micromachining by high precision optical metrology and image analysis. Precis. Eng. 2017, 50, 8-19. [CrossRef]

14. Wang, Y.; Zhang, Z.; Zhang, G.; Wang, B.; Zhang, W. Study on immersion waterjet assisted laser micromachining process. J. Mater. Process. Technol. 2018, 262, 290-298. [CrossRef]

15. James, S.; Sonate, A. Experimental study on micromachining of CFRP/Ti stacks using micro ultrasonic machining process. Int. J. Adv. Manuf. Technol. 2018, 95, 1539-1547. [CrossRef]

16. Dabir-Moghaddam, N.; Song, H.; Wu, B. Modeling of cavitating flow induced by an ultrasonic horn above a solid target with a microhole. J. Manuf. Process. 2018, 32, 327-336. [CrossRef]

17. Jain, V.K. Magnetic field assisted abrasive based micro-/nano-finishing. J. Mater. Process. Technol. 2009, 209, 6022-6038. [CrossRef]

18. Selada, A.; Manaia, A.; Vieira, M.T.; Pouzada, A.S. Effect of LBM and large-area EBM finishing on micro-injection moulding surfaces. Int. J. Adv. Manuf. Technol. 2011, 52, 171-182. [CrossRef]

19. Bruschi, S.; Tristo, G.; Rysava, Z.; Bariani, P.F.; Umbrello, D.; De Chiffre, L. Environmentally clean micromilling of electron beam melted Ti6Al4V. J. Clean. Prod. 2016, 133, 932-941. [CrossRef]

20. Pratap, T.; Patra, K. Micro Ball-End Milling - An Emerging Manufacturing Technology for Micro-feature patterns. Int. J. Adv. Manuf. Technol. 2018, 94, 2821-2845. [CrossRef]

21. Beruvides, G.; Quiza, R.; Rivas, M.; Castaño, F.; Haber, R.E. Online detection of run out in microdrilling of tungsten and titanium alloys. Int. J. Adv. Manuf. Technol. 2014, 74, 1567-1575. [CrossRef]

22. Liao, Z.; Axinte, D.A. On monitoring chip formation, penetration depth and cutting malfunctions in bone micro-drilling via acoustic emission. J. Mater. Process. Technol. 2016, 229, 82-93. [CrossRef]

23. Patra, K.; Jha, A.K.; Szalay, T.; Ranjan, J.; Monostori, L. Artificial neural network based tool condition monitoring in micro mechanical peck drilling using thrust force signals. Precis. Eng. 2017, 8, 279-291. [CrossRef]

24. Mikołajczyk, T.; Nowicki, K.; Kłodowski, A.; Pimenov, D.Y. Neural network approach for automatic image analysis of cutting edge wear. Mech. Syst. Signal. Process. 2017, 88, 100-110. [CrossRef]

25. Malekian, M.; Park, S.S.; Jun, M.B.G. Tool wear monitoring of micro-milling operations. J. Mater. Process. Technol. 2009, 209, 4903-4914. [CrossRef]

26. Kim, D.W.; Lee, Y.S.; Park, M.S.; Chu, C.N. Tool life improvement by peck drilling and thrust force monitoring during deep-micro-hole drilling of steel. Int. J. Mach. Tool. Manuf. 2009, 49, 246-255. [CrossRef]

27. Ravisubramanian, S.; Shunmugam, M.S. On reliable measurement of micro drilling forces and identification of different phases. Measurement 2015, 73, 335-340. [CrossRef]

28. García Plaza, E.; Núñez López, P.J. Analysis of cutting force signals by wavelet packet transform for surface roughness monitoring in CNC turning. Mech. Syst. Signal. Process. 2018, 98, 634-651. [CrossRef]

29. Efkolidis, N.; Hernández, C.G.; Talón, J.L.H.; Kyratsis, P. Modelling and prediction of thrust force and torque in drilling operations of Al7075 using ANN and RSM methodologies. Stroj. Vestn. J. Mech. Eng. 2018, 64, 351-361. [CrossRef]

30. Oh, Y.T.; Kwon, W.T.; Chu, C.N. Drilling torque control using spindle motor current and its effect on tool wear. Int. J. Adv. Manuf. Technol. 2004, 24, 327-334. [CrossRef] 
31. Garg, S.; Patra, K.; Pal, S.K.; Chakraborty, D. Effect of different basis functions on a radial basis function network in prediction of drill flank wear from motor current signals. Soft Computing 2008, 12, 777-787. [CrossRef]

32. Pimenov, D.Y.; Bustillo, A.; Mikolajczyk, T. Artificial intelligence for automatic prediction of required surface roughness by monitoring wear on face mill teeth. J. Intell. Manuf. 2018, 29, 1045-1061. [CrossRef]

33. García-Ordás, M.T.; Alegre-Gutiérrez, E.; Alaiz-Rodríguez, R.; González-Castro, V. Tool wear monitoring using an online, automatic and low cost system based on local texture. Mech. Syst. Signal. Process. 2018, 112, 98-112. [CrossRef]

34. Mikołajczyk, T.; Nowicki, K.; Bustillo, A.; Pimenov, D.Y. Predicting tool life in turning operations using neural networks and image processing. Mech. Syst. Signal. Process. 2018, 104, 503-513. [CrossRef]

35. Huang, C.R.; Lu, M.C.; Lu, C.E.; Hsu, Y.W. Study of spindle vibration signals for tool breakage monitoring in microdrilling. In Proceedings of the 8th World congress on Intelligent Control and Automation, Taipei, Taiwan, 21-25 June 2011. [CrossRef]

36. García Plaza, E.; Núñez López, P.J. Application of the wavelet packet transform to vibration signals for surface roughness monitoring in CNC turning operations. Mech. Syst. Signal. Process. 2018, 98, 902-919. [CrossRef]

37. Patra, K. Acoustic emission based tool condition monitoring system in drilling. In Proceedings of the World Congress on Engineering (WCE 2011), London, UK, 6-8 July 2011; Volume 3, pp. 2126-2130.

38. Yesilli, M.C.; Khasawneh, F.A.; Otto, A. On transfer learning for chatter detection in turning using wavelet packet transform and ensemble empirical mode decomposition. CIRP J. Manuf. Sci. Technol. 2019, in press. [CrossRef]

39. García Plaza, E.; Núñez López, P.J.; Beamud González, E.M. Efficiency of vibration signal feature extraction for surface finish monitoring in CNC machining. J. Manuf. Process. 2019, 44, 145-157. [CrossRef]

40. Fu, L.; Ling, S.F.; Tseng, C.H. On-line breakage monitoring of small drills with input impedance of driving motor. Mech. System. Signal. Process. 2007, 21, 457-465. [CrossRef]

41. Segreto, T.; Karam, S.; Simeone, A.; Teti, R. Residual Stress Assessment in Inconel 718 Machining Through Wavelet Sensor Signal Analysis and Sensor Fusion Pattern Recognition. Procedia CIRP 2013, 9, 103-108. [CrossRef]

42. García Plaza, E.; Núñez López, P.J.; Beamud González, E.M. Multi-sensor data fusion for real-time surface quality control in automated machining systems. Sensors 2018, 18, 4381. [CrossRef]

43. Rahman, M.; Zhou, Q.; Hong, G.S. On-line cutting state recognition in turning using a neural network. Int. J. Adv. Manuf. Technol. 1995, 10, 87-92. [CrossRef]

44. Sharma, V.S.; Dhiman, S.; Sehgal, R.; Sharma, S.K. Estimation of cutting forces and surface roughness for hard turning using neural networks. J. Intell. Manuf. 2008, 19, 473-483. [CrossRef]

45. Patra, K.; Jha, A.K.; Szalay, T. Tool condition monitoring in micro-drilling using vibrations signals and artificial neural network. In Proceedings of the 2017 International Conference on Industrial Engineering, Applications and Manufacturing (ICIEAM), Saint Petersburg, Russia, 16-19 May 2017.

46. Wang, H.; Li, S.; Song, L.; Cui, L. A novel convolutional neural network based fault recognition method via image fusion of multi-vibration-signals. Comput. Ind. 2019, 105, 182-190. [CrossRef]

47. Cao, X.C.; Chen, B.Q.; Yao, B.; He, W.P. Combining translation-invariant wavelet frames and convolutional neural network for intelligent tool wear state identification. Comput. Ind. 2019, 106, 71-84. [CrossRef]

48. Beruvides, G.; Quiza, R.; Del Toro, R.; Haber, R.E. Sensoring systems and signal analysis to monitor tool wear in microdrilling operations on a sintered tungsten-copper composite material. Sens. Actuat. A Phys. 2013, 199, 165-175. [CrossRef]

49. Anand, R.S.; Patra, K.; Steiner, M.; Biermann, D. Mechanistic modeling of micro drilling cutting forces. Int. J. Adv. Manuf. Technol. 2017, 88, 241-254. [CrossRef]

50. Imran, M.; Mativenga, P.T.; Withers, P.J. Assessment of machining performanceusing the wear map approach in micro-drilling.Int. J. Adv. Manuf. Technol. 2012, 59, 119-126. [CrossRef]

51. Kondo, E.; Kamo, R.; Murakami, H. Monitoring of burr and prefailure phase caused by tool wear in micro-drilling operations using thrust force signals. J. Adv. Mech. Des. Syst. Manuf. 2012, 6, 875-884. [CrossRef]

52. Patra, K.; Pal, S.K.; Bhattacharyya, K. Fuzzy radial basis function (FRBF) network based tool condition monitoring system using vibration signals. Mach. Sci. Tech. 2010, 14, 280-300. [CrossRef] 
53. Ranjan, J.; Patra, K.; Szalay, T. Application of Artificial Neural Network and Wavelet Packet Transform for Vibration Signal Based Monitoring in Mechanical Micro-drilling. In Proceedings of the 2015 International Conference on Futuristic Trends on Computational Analysis and Knowledge Management (ABLAZE), Noida, India, 25-27 February 2015.

54. Anand, R.S.; Patra, K. Cutting Forces and Hole Quality Analysis in Micro-drilling of CFRP. Mat. Manuf. Proc. 2018, 33, 1369-1377. [CrossRef]

55. Gadelmawla, E.S. Simple and Efficient Algorithms for Roundness 490 Evaluation from the Coordinate Measurement Data. Measurement 2010, 43, 223-235. [CrossRef]

(C) 2020 by the authors. Licensee MDPI, Basel, Switzerland. This article is an open access article distributed under the terms and conditions of the Creative Commons Attribution (CC BY) license (http://creativecommons.org/licenses/by/4.0/). 